\title{
Gravidez e Tumor Filodes Bilateral: Uma Associação Rara
}

\author{
Pregnancy and Bilateral Phyllode Tumor: A Rare Association
}

Ary Wanderley de Carvalho Jr., Samara Maria Messias da Silva Pabline Barbosa Lima Almeida, Osterno Queiroz da Silva Luiza Emylce P. R. Schumaltz, Juarez Antônio de Sousa, Marco Aurélio Albernaz

\begin{abstract}
RESUMO
É apresentado um caso de tumor filodes bilateral benigno diagnosticado durante a gravidez, que apresentou crescimento rápido, atingindo grandes dimensões. O tratamento foi mastectomia bilateral total na $20^{a}$ semana de gestação. Houve boa evolução pós-operatória e o parto ocorreu na $40^{a}$ semana, com recém-nascido vivo do sexo masculino. São discutidos os achados clínicos e anatomopatológicos e a evolução de gravidez.
\end{abstract}

PALAVRAS-CHAVE: Tumor filodes benigno. Complicações da gravidez.

\section{Introdução}

O tumor filodes, também denominado cystosarcoma phyllodes em razão das projeções foliácias de tecido tumoral no interior de cavidades císticas, é uma neoplasia mista de tecido epitelial e conectivo, caracterizando-se por um crescimento rápido e podendo apresentar grandes dimensões no momento do diagnóstico ${ }^{1,3,7,8,9}$.

É um tumor raro, representando $0,5 \%$ de todos tumores mamários. A recidiva é freqüente porém raramente metastatiza e, quando isto ocorre, geralmente é por via hematogênica. A bilateralidade

Setor de Mastologia do Serviço de Residência Média de Ginecologia e Obstetrícia do Hospital Materno Infantil de Goiânia-GO.

Correspondência:

Juarez Antônio de Sousa

Rua 7, 247/1303, S. Oeste - 74.110-090 - Goiânia - GO

Tel: (062) 223-6281 / (062) 971-6792 / FAX: (062) 223-6281

E-mail: juarezana@persogo.com.br é rara, representando aproximadamente $1 \%{ }^{8}$.

O seu crescimento depende de alguns fatores, tais como traumatismo, lactação e gravidez. A gestação, em especial, pode propiciar um ambiente ideal para o seu crescimento, pelos altos níveis de estrogênio e progesterona ${ }^{8}$.

\section{Relato do Caso}

M.B.M., 28 anos, procurou o Serviço de Mastologia do Hospital Materno Infantil de GoiâniaGO, com aumento do volume mamário bilateral há 4 meses, época em que engravidou. Apresentava dificuldade respiratória e para se manter na posição ortostática (Figura 1). Nesta época apresentava idade gestacional de 19 semanas. A menarca havia ocorrido aos 12 anos. Era tercigesta, secundipara. Sua mãe havia falecido de câncer de mama. 


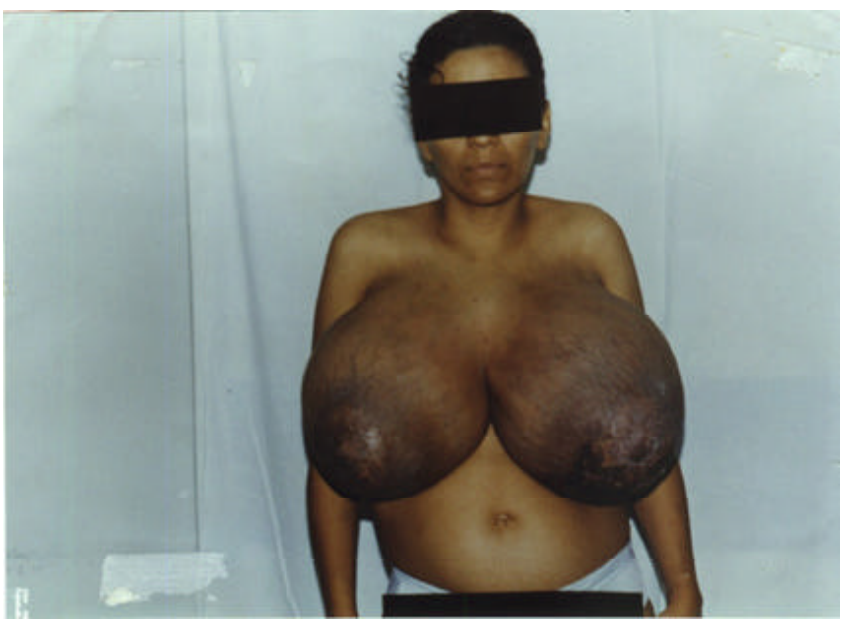

Figura 1 - Paciente com 19 semanas de gestação. Mamas com vascularização aumentada, áreas de hipercromia e ulcerações. Demarcação pré-operatória.

Ao exame físico, as mamas eram de grande volume, medindo aproximadamente $30 \mathrm{~cm}$ em seus maiores diâmetros, com vascularização aumentada. Havia áreas de hipercromia associadas a lesões ulceradas e outras crostosas. Durante o exame inicial não se palparam nódulos.

A ultra-sonografia mamária foi compativel com gigantomastia bilateral associada a acentuados sinais flogísticos com nodulações sólidas em todos os quadrantes, principalmente nos súpero-laterais.

$\mathrm{Na} 20^{a}$ semana de gestação a paciente foi internada e programado debridamento mamário com uma possivel mamoplastia redutora (Figura 2). Durante o procedimento cirúrgico constatou-se que as mamas se apresentavam com aspecto tumoral comprometendo todo o parênquima mamário, não havendo condições técnicas para se preservar tecido mamário. Diante do achado decidiu-se realizar mastectomia total bilateral, tendo $\mathrm{o}$ ato transcorrido sem intercorrências.

$\mathrm{O}$ antomopatológico evidenciou à macroscopia mama direita e esquerda pesando 6,4 $\mathrm{kg}$ e $6,5 \mathrm{~kg}$, respectivamente. A microscopia revelou neoformação mista, fibro-epitelial, notando-se estruturas ductais ramificadas, revestidas por epitélio cúbico simples, tendo subjacente camada de células mioepiteliais, não se notando evidências de atipias citológicas. O estroma apresentava padrão fibroso, hipercelularidade acentuada nas áreas circunjacentes às estruturas ductais e ausência de atipias celulares. A conclusão histopatológica foi de um tumor filodes bilateral, variedade benigna (Figura 3).

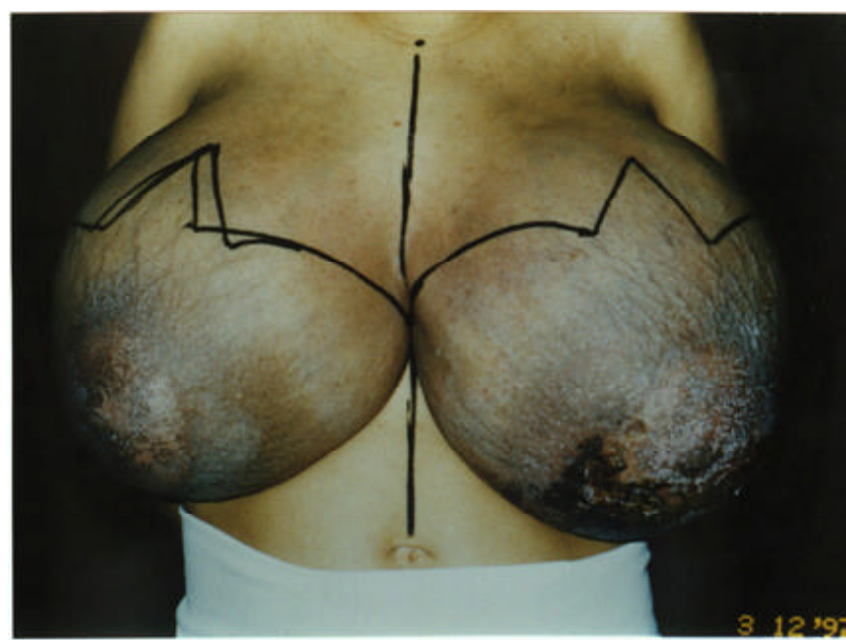

Figura 2 - Demarcação pré-operatória para mamoplastia redutora.

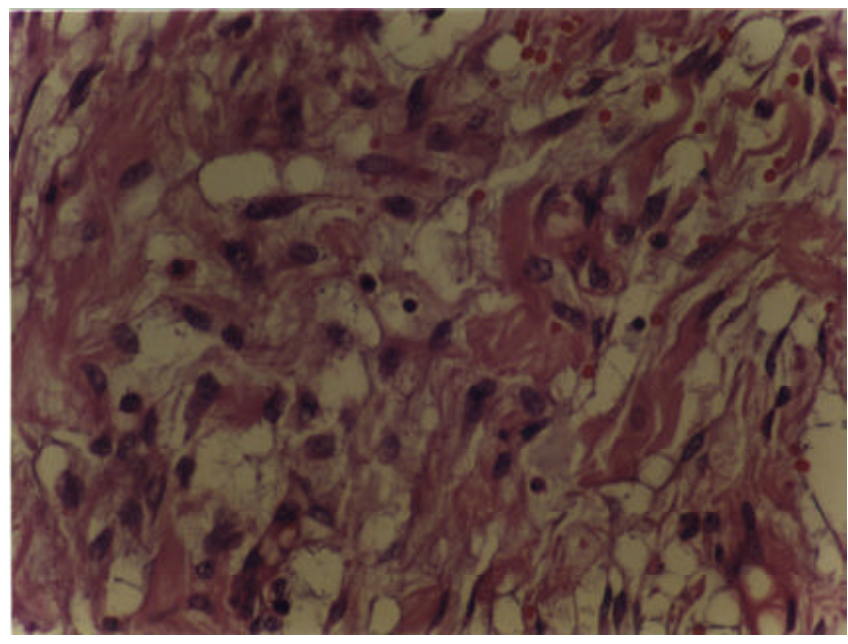

Figura 3 - Aspecto microscópico do componente estromal com celularidade aumentada (HE-200X)

O pós-operatório transcorreu sem anormalidades, tendo a paciente recebido alta no $7^{\circ}$ dia. A gravidez progrediu normalmente após a cirurgia, evoluindo para parto transpélvico, com recém-nascido vivo a termo do sexo masculino sem anormalidades. $\mathrm{O}$ aspecto cirúrgico apresentavase satisfatório no segundo mês pós-parto.

\section{Discussão}

O tumor filodes, primeiramente descrito por Müller em 1838, é uma neoplasia mamária pouco freqüente, geralmente benigna, mas que, classicamente, apresenta variantes benigna, "borderline" e maligna. Os tumores são grandes, 
com diâmetros de 6 a $8 \mathrm{~cm}$ ou mais, geralmente nodulares, pouco dolorosos e móveis ${ }^{2,3,4,6,8}$.

$\mathrm{O}$ aspecto histológico assemelha-se muito ao do fibroadenoma, no entanto difere deste por possuir estroma hipercelular. É uma neoplasia mista, acometendo tanto o estroma como o componente epitelial. A presença de receptores de estrógeno e progesterona no tumor filodes sugere que a ação hormonal pode afetar o crescimento do tumor, o que explicaria o rápido crescimento tumoral na gestação ${ }^{3,5}$.

O tratamento deve ser feito com excisão ampla com uma margem de pelo menos $2 \mathrm{~cm}$. Como estes tumores, muitas vezes, já se apresentam grandes no momento do diagnóstico, o tratamento pode, embora raramente, culminar com uma mastectomia. Não há necessidade de linfadenectomia axilar, pois raramente os linfonodos estão comprometidos ${ }^{1,2,8,9}$.

As recidivas locais usualmente indicam excisão inicial inadequada, sendo necessária nova intervenção cirúrgica para remoção das áreas de recorrência ${ }^{1}$.

O presente relato mostra um caso raro de tumor filodes bilateral na gestação, que apresentou crescimento rápido, influenciado pela hiperplasia fisiológica da gravidez, culminando com mastectomia total bilateral e apresentando resultado terapêutico satisfatório.

\section{SUMMARY}

A rare case of bilateral benign phyllode tumor of the breast with fast growth during pregnancy and reaching great dimensions is presented. The patient was submitted to bilateral mastectomy on the 20th week of pregnancy. She had a good postoperative evolution and vaginal delivery occurred on the 40th week, when a healthy boy was born. The clinical and surgical features, the pathologic findings and the evolution of pregnancy are discussed.

KEY WORDS: Phyllode tumor: benign. Complication of pregnancy.

\section{Referências}

1. Bennett IC, Khan A, De Freitas R, Chaudary MA, Millis RR. Phyllodes tumours: a clinicopathological review of 30 cases. Aust N Z J Surg 1992; 62:628-33.

2. Buchanan EB. Cystosarcoma phyllodes and its surgical management. Am Surg 1995; 61:350-5.

3. Cabaret V, Delobelle-Deroide A, Vilain MO. Les tumeurs phyllodes. Arch Anat Cytol Pathol 1995; 43: $59-72$.

4. Henriques FAM, Magrin AM, Borges SZ, Pereira MAQF, Araújo SS, Mousinho AP, et al. Tumor filodes. Casuística da Unidade de Mastologia do HBDF. Rev Bras Mastol 1998; 8:13-20.

5. Lang BA, Vermousek I, Simickova M, Cernoch M, Nekulova M, Pacovsky $Z$, et al. Phylloid breast tumors and three steroid hormone receptors. Neoplasma 1997; 44:53-7.

6. Pérez JA, Poblete SMT, Santolaya CR. Tumor filodes mamário: una revisión clinicopatológica de 14 casos. Rev Méd Chile 1995; 123: 1379-86.

7. Reinfuss M, Mitus J, Stelmach A. Phyllodes tumor of the breast. Strahlenther Onkol 1995; 1:5-11.

8. Seben RL, Bohn L, Xavier NL, Osório JS. Cystosarcoma phyllodes na gestação: relato de um caso e revisão. Rev AMRIGS 1985; 29:49-52.

9. Uribe Barreto A, Bravo G, Uribe OA, Viada R, Capetillo Fuentes M, Villarroel T. Tumor filodes: diagnóstico y tratamiento, Rev Chil Obstet Ginecol 1995; 60: 17-22. 